Journal of Zhejiang University-SCIENCE B (Biomedicine \& Biotechnology)

ISSN 1673-1581 (Print); ISSN 1862-1783 (Online)

www.zju.edu.cn/jzus; www.springerlink.com

E-mail: jzus@zju.edu.cn

\title{
Review:
}

\section{Chemokines and their receptors in lung cancer progression and metastasis}

\author{
Zeng-hui $\mathrm{CHENG}^{1,2}$, Yu-xin SHI ${ }^{1}$, Min YUAN ${ }^{1}$, Dan XIONG ${ }^{3}$, Jiang-hua ZHENG ${ }^{\dagger 3}$, Zhi-yong ZHANG ${ }^{\dagger 1}$ \\ ('Department of Radiology, Shanghai Public Health Clinical Center, Fudan University, Shanghai 201508, China) \\ ( ${ }^{2}$ Department of Radiology, Qingpu Branch of Zhongshan Hospital, Fudan University, Shanghai 201700, China) \\ ( ${ }^{3}$ Department of Clinical Laboratory, Shanghai Public Health Clinical Center, Fudan University, Shanghai 201508, China) \\ †E-mail: zhengjianghua2014@163.com; zhangzy@shaphc.org \\ Received Oct. 27, 2015; Revision accepted Jan. 5, 2016; Crosschecked Apr. 15, 2016
}

\begin{abstract}
Lung cancer is the leading cause of cancer-related mortality around the world. Despite advancements in diagnosis, surgical techniques, and neoadjuvant chemoradiotherapy over the last decade, the mortality rate is still high and the 5 -year survival is a dismal $15 \%$. Fortunately, early detection by low-dose computed tomography (LDCT) scans has reduced mortality by $20 \%$; yet, overall, 5 -year-survival remains low at less than $20 \%$. Therefore, in order to ameliorate this situation, a thorough understanding of the underlying molecular mechanisms is urgently needed. Chemokines and their receptors, crucial microenvironmental factors, play important roles in lung tumor genesis, progression, and metastasis, and exploring the mechanisms of this might bring new insights into early diagnosis and precisely targeted treatment. Consequently, this review will mainly focus on recent advancements on the axes of chemokines and their receptors of lung cancer.
\end{abstract}

Key words: Lung cancer, Chemokines, Tumor progression, Metastasis http://dx.doi.org/10.1631/jzus.B1500258

CLC number: R734.2; R34

\section{Introduction}

Lung cancer is the leading cause of cancerrelated mortality in both genders worldwide. In China, with its serious air pollution and high tobacco consumption, the incidence and mortality of lung cancer have increased rapidly in recent years. It has been reported that approximately 500000 patients were diagnosed and 430000 died from lung cancer in 2005, and the number of deaths is anticipated to be more than one million by 2025 (Yang et al., 2005a; 2005b; Dong et al., 2010). Histologically, lung cancer has

\footnotetext{
${ }^{\ddagger}$ Corresponding authors

* Project supported by the Science and Technology Commission of Shanghai Municipality (No. 14140901400), the Natural Science Foundation of Shanghai (No. 13ZR1435000), and the National Natural Science Foundation of China (No. 81372318)

(1) ORCID: Zeng-hui CHENG, http://orcid.org/0000-0001-8966-4329

(C) Zhejiang University and Springer-Verlag Berlin Heidelberg 2016
}

been classified into non-small cell lung cancer (NSCLC) and small cell lung cancer (SCLC); the former, originating from respiratory epithelial cells, accounts for $80 \%$ of cases with subtypes of adenocarcinoma, squamous cell carcinoma, and large cell carcinoma in order of incidence rate; the latter, from cells with differentiation in neuroendocrine along the bronchial tree, accounts for the remaining 20\% (Goldstraw et al., 2007; Groome et al., 2007; Sutherland and Berns, 2010).

Despite advances in diagnosis, staging, surgical techniques, and neoadjuvant chemoradiotherapy over the last decade, the mortality rate of lung cancer is still high and 5-year survival is only $15 \%$ (Siegel et al., 2012a; 2012b). As a result of a lack of early specific signs and symptoms, most of these patients are diagnosed at advanced stages where surgery is no longer feasible. Fortunately, early detection with a lung cancer screening program using low-dose 
computed tomography (LDCT) scans has recently brought bright prospects, and the mortality rate has reduced by $20 \%$ (National Lung Screening Trial Research, 2011). Nevertheless, overall, 5-yearsurvival remains low, at less than $20 \%$ (Keith and Miller, 2013). Therefore, early detection is only the first step; personalized precise treatments following detection, based on molecular mechanisms, are also crucial; these treatments either fight tumor cells directly or modify the tumor microenvironment indirectly (Burger and Gribben, 2014). Chemokines seem to be central in this microenvironment by promoting leukocyte infiltration and tumorogenesis (Mukaida and Baba, 2012).

Chemokines, a superfamily of inducible, secreted, heparin-binding proteins, are structurally homologous and are involved in tumor growth and metastasis (Keeley et al., 2011). The receptors, a superfamily of seven transmembrane spanning proteins coupled to G-protein-coupled-receptors (GPCRs), are classified into four major groups based on the pattern of cysteine residues: $\mathrm{CXC}, \mathrm{CC}, \mathrm{C}$, and CX3C, where $\mathrm{C}$ stands for cysteine and $\mathrm{X}$ for non-cysteine amino acids (Zlotnik and Yoshie, 2000). Functionally speaking, chemokines are grouped into inflammatory and homeostatic; the former are induced by inflammation while the latter are constitutively expressed and involved in homeostatic immune regulation (Sarvaiya et al., 2013). Their binding leads to conformational changes and the following activation of signaling pathways, which play an important role in both normal inflammatory reactions if the expression is regular and abnormal reactions if aberrant, leading to constitutive activation of oncogenes, inactivation of tumor suppressor genes, or altered expression of transcription factors. This consequently results in tumor angiogenesis, growth, epithelial mesenchymal transition (EMT), and further metastasis (Richmond, 2002; Sparmann and Bar-Sagi, 2004; Mantovani et al., 2010).

To date, the most studied chemokine axis in lung cancer is CXCL12/CXCR4, which has been proved to be related to greater invasiveness and higher potential for metastasis (Burger et al., 2011; Saintigny and Burger, 2012), and many new drugs targeting this axis are under development (Peled et al., 2012). It is the case that other chemokine axes have also been investigated. Therefore, it is necessary to review the role of chemokines and their receptors in lung cancer
(Table 1), particularly the most common histological type, NSCLC, in progression and metastasis, which might provide insights into the molecular mechanisms of lung tumorigenesis and progression, and consequently assist early diagnoses and targeted treatments.

\section{CXCL12/CXCR4}

CXCR4, the most frequently overexpressed and thoroughly studied chemokine receptor in malignancies, is present in many different types of human cancers, including lung cancer (Balkwill, 2004; Burger and Kipps, 2006), the expression of which is upregulated in hypoxia, as might be encountered in a tumor microenvironment (Schioppa et al., 2003; Phillips et al., 2005). The corresponding ligand, CXCL12, is constitutively expressed in tissues that are targets of metastases (Burger and Kipps, 2006).

In lung cancer, the CXCL12/CXCR4 axis plays a crucial role in migration and metastasis. NSCLC cells expressing CXCR4 were noticed to migrate to tissues or organs with a high level of CXCL12, such as lymph nodes, contralateral lung, liver, brain, and bone marrow (Phillips et al., 2003; Belperio et al., 2004; Su et al., 2005; Wagner et al., 2009), even if the primary tumor was resected, just as Wang et al. (2014) found that a high expression level of CXCR4 correlated with brain-specific metastasis following complete resection of NSCLC. In addition, the axis can promote cell proliferation, tumor growth, and angiogenesis (Phillips et al., 2003; Wald et al., 2011), and CXCR4 also appears to have an effect on the biology of cancer stem cells, which possess high self-renewal capacities, potential recapitulation of tumors in ectopic settings, and drug-resistant properties in NSCLC (Eramo et al., 2008; Wald et al., 2011). NSCLC cells expressing CXCR4 are strong candidates for those stem cells that maintain their property of self-renewal through a CXCR4-mediated signal transducer and activator of transcription 3 (STAT3) pathway (Jung et al., 2013). In addition, CXCR4 might act to the transcriptional factor 5T4 downstream in EMT and consequently in migration (Damelin et al., 2011). Hence, high expression of CXCL12/CXCR4 is correlated with poor prognosis in NSCLC (Suzuki et al., 2008), and a substantial body 
Table 1 Summary of chemokines/receptors related to lung tumor progression and metastasis

\begin{tabular}{|c|c|c|c|}
\hline Chemokine/Receptor & Pro-tumor & Anti-tumor & Reference \\
\hline $\begin{array}{c}\text { CXCL12/CXCR4 } \\
\text { (co-expression: Nrf2/EGFR/uPAR) }\end{array}$ & $\sqrt{ }$ & & $\begin{array}{l}\text { Phillips et al., 2003; Belperio et al., 2004; Su et al., } \\
\text { 2005; Eramo et al., 2008; Wagner et al., 2009; } \\
\text { Damelin et al., 2011; Montuori et al., 2011; Wald } \\
\text { et al., 2011; Almasi et al., 2013; Jung et al., 2013; } \\
\text { Hu et al., 2014; Li and Tai, 2014; Wang et al., 2014 }\end{array}$ \\
\hline $\begin{array}{c}\mathrm{Ub} / \mathrm{CXCR} 4 \\
\text { (extracellular Ub) }\end{array}$ & $\sqrt{ }$ & & Majetschak, 2011; Yan et al., 2013 \\
\hline CXCL1/5/8/CXCR2 & $\sqrt{ }$ & $\sqrt{ }$ & $\begin{array}{l}\text { Luppi et al., 2007; Maxwell et al., 2007; Acosta } \\
\text { et al., 2008; Sun et al., 2008; Yanagawa et al., } \\
\text { 2009; Saintigny et al., } 2013\end{array}$ \\
\hline CCL2/CCR2 & $\sqrt{ }$ & $\sqrt{ }$ & $\begin{array}{l}\text { Li and Tai, 2013; 2014; Zhang X.W. et al., 2013; } \\
\text { Chen et al., 2015; }\end{array}$ \\
\hline CCL19/21/CCR7 & $\sqrt{ }$ & $\sqrt{ }$ & $\begin{array}{l}\text { Muller et al., 2001; Hillinger et al., 2003; Cabioglu } \\
\text { et al., 2007; Cao et al., 2007; Itakura et al., 2013; } \\
\text { Sharma et al., 2013; Zhang Q. et al., } 2013\end{array}$ \\
\hline CCL25/CCR9 & $\sqrt{ }$ & & Gupta et al., 2014 \\
\hline CCL4/CCR5 & $\sqrt{ }$ & & Lee et al., 2012; Mango et al., 2014 \\
\hline $\begin{array}{l}\text { Atypical chemokine receptors } \\
\text { (DARC/D6/CCX-CKR) }\end{array}$ & & $\sqrt{ }$ & Addison et al., 2004; Wu et al., 2013 \\
\hline
\end{tabular}

Nrf2: NF-E2-related factor 2; EGFR: epidermal growth factor receptor; uPAR: urokinase plasminogen activator receptor; Ub: ubiquitin; DARC: Duffy antigen receptor for chemokines; CCX-CKR: ChemocentryX chemokine receptor. References in bold: chemokines/ receptors with anti-tumor effect

of literature supports the fact that interruption of this ligand-receptor interaction can inhibit cancer cell migration and metastasis (Burger and Kipps, 2006; Sun et al., 2010; Xie et al., 2014).

Besides the above, some co-expression proteins and receptors can produce synergistic effects. Nrf2, a key transcriptional factor, regulates antioxidant response to accumulated oxidative reaction with tumor growth (Bauer et al., 2013). Its abnormal expression, together with CXCR4, was noticed to contribute to large tumor size, poor differentiation, an advanced TNM stage, lymph node metastasis, and distant metastasis in NSCLC (Hu et al., 2014). However, the mechanism underlying this needs to be elaborated. Concomitant overexpression of EGFR and CXCR4 is associated with a worse prognosis in NSCLC, and EGFR can enhance the expression of CXCR4 in NSCLC cells through the PI-3K pathway (Al Zobair et al., 2013). Urokinase plasminogen activator receptor (UPAR), a glycoprotein of the Ly-6 family, takes effect in tumorigenesis (Ploug and Ellis, 1994; Dass et al., 2008). In human malignancies, uPAR overexpression is associated with an increased propensity for cancer progression and metastasis (Mazar, 2008), and intact UPAR and its cleaved forms are testified to be associated with poor prognosis in
NSCLC and SCLC (Almasi et al., 2013). uPAR could interfere in CXCR4 activity and regulate the adhesive and migratory ability of CXCR4-expressing cells (Montuori et al., 2011). Co-expression of uPAR and CXCR4 promotes tumor growth and metastasis in SCLC (Li and Tai, 2014). Therefore, the role of the CXCL12/CXCR4 axis in lung tumor progression and metastasis can be enhanced when these proteins are aberrantly co-expressed. Targeting these proteins together with the CXCL12/CXCR4 axis would hamper lung cancer progression.

\section{Ubiquitin/CXCR4}

Ubiquitin (Ub), a post-translational protein modifier inside the cell, was detected in increased concentrations during various disease processes (Majetschak, 2011). Extracellular Ub, a recently identified new ligand for CXCR4, was found to act as an anti-inflammatory immune modulator in hematopoietic cells, and to induce suppressive and apoptotic effects on these cells (Saini et al., 2010; Majetschak, 2011). Recent studies on the potential role of extracellular Ub in non-hematological cells found that it had anti-apoptotic effects via activation of the PI3K 
pathway and was related to cell migration in epithelial cells. To date, only a few investigations have been carried out on the Ub-CXCR4 axis, which showed that it played an important part in acute lung infectionenhanced lung tumor metastasis (Majetschak, 2011; Yan et al., 2013). Nevertheless, the effect on human lung tumors with or without acute inflammation setting of the axis should be further investigated and the mechanism should be elucidated in the future.

\section{CXCL1/CXCR2}

CXCL1, also called growth-related oncogene protein- $\alpha$ (GRO- $\alpha)$ or melanoma growth stimulatory activity factor (MGSA), is a polypeptide initially isolated from Hs294 human melanoma cells, and belongs to the Glu-Leu-Arg (ELR+) chemokine family that is primarily chemotactic for endothelial cells and neutrophils. These chemokines are potent promoters of angiogenesis by recruiting neutrophils to synthesize and store angiogenic molecules like vascular endothelial growth factors (VEGFs) (Scapini et al., 2004), which can induce CXCL1 release via JNK and PI-3K-dependent pathways in human lung carcinoma epithelial cells (Lo et al., 2013). CXCL1 was also found to play a pivotal role in thrombininduced angiogenesis (Caunt et al., 2006).

CXCR2, a member of GPCRs, is the receptor of ELR+ CXC chemokines such as CXCL1, CXCL2, CXCL3, CXCL5, and CXCL7 (PPBP). CXCL6 and CXCL8 (interleukin-8 (IL-8)) are shared ligands of CXCR1 and CXCR2. Alveolar epithelial cells transformed by oncogenic KRAS were reported to express high levels of CXCR2 ligands, which recruited inflammatory and endothelial cells and promoted progression of premalignant alveolar lesions to lung adenocarcinoma (Wislez et al., 2006), and biopsy specimens of NSCLC had also been found to express high concentrations of CXCR2 ligands (CXCL1, CXCL5, and CXCL8) and type-2 cytokines (IL-4, IL-5, IL-10, and IL-13) (Arenberg et al., 1998). NSCLC cell lines and lung adenocarcinomas expressing CXCR2 were noticed to be associated with smoking, CXCL5 expression and poor prognosis by promoting invasion and metastasis (Saintigny et al., 2013). In addition, IL-17 was reported to augment secretion of an array of angiogenic CXC chemokines, including CXCL1, CXCL5, CXCL6, and CXCL8 by three different NSCLC cell lines (Numasaki et al., 2005), and activation of the IL-8/CXCR2 axis, followed by neutrophils recruitments and eutrophil elastase release, was found to promote lung tumorigenesis in the inflammation settings (Gong et al., 2013).

The role of CXCR2 in tumor cells is debatable. Some studies have shown that it could promote cell proliferation, migration, and invasion (Luppi et al., 2007; Sun et al., 2008; Yanagawa et al., 2009) and also assist cancer cells in evading stress-induced apoptosis (Maxwell et al., 2007), suggesting that it is a poor prognostic factor, while others have reported recently that depletion of CXCR2 could not only delay replicative senescence but also impair the senescence response to oncogenic signals, suggesting its role in tumor suppression (Acosta et al., 2008). Hence, more studies should be conducted to testify the exact role of this axis hereafter.

\section{CCL2/CCR2}

CCL2, also known as monocyte chemoattractant protein-1 (MCP-1), interacts with its receptor CCR2 and then takes effect not only on mediation of monocytes recruitment during inflammation and immunological reaction, but also on tumor progression and metastasis (Kudo-Saito et al., 2013). Investigations from human lung adenocarcinoma cells showed that the expression of MCP-1/CCL2 was induced by activation of protease-activated receptor 2 (PAR2) through matrix metalloproteinase-1 (MMP-1) release which was mediated by the thromboxane A2 receptor (Li and Tai, 2014), and activation of the latter receptor could increase the expression of MCP-1/CCL2 and recruit macrophages, thereby promoting lung cancer invasion ( $\mathrm{Li}$ and Tai, 2013). In addition, it has been recently reported that the CCL2/CCR2 axis could activate STAT3-Twist signaling corporately and subsequently enhance EMT induced by IL-6 (Chen et al., 2015), thus leading to lung cancer metastasis. Nevertheless, a study of 134 NSCLC surgical specimens revealed that MCP-1/CCL2 was detected much more than CCR2 with no positive correlation, and overexpression of MCP-1/CCL2 was a good independent prognostic factor for NSCLC patients 
(Zhang X.W. et al., 2013). Therefore, more studies are warranted to testify the real role of this axis in human lung cancers.

\section{CCL19/21/CCR7}

CCR7, another member of GPCRs, has two ligands, CCL19 and CCL21, is preferentially expressed on naive $\mathrm{T}$ cells and mature dendritic cells (DCs), and binds to its ligands in promotion of migration, invasion, and chemotaxis of some cells, including T cells, B cells, natural killer (NK) cells, mature DCs, and some tumor cells (Ding et al., 2003; Iijima et al., 2005).

Overexpression of CCR7 was demonstrated to closely correlate with invasion and metastasis of NSCLC in most investigations (Muller et al., 2001; Cabioglu et al., 2007), and the underlying mechanism might be up-regulation of heparanase via specificity protein-1 (Sp1) to promote invasion (Zhang Q. et al., 2013). However, other studies found that CCL19 had an antitumor effect with corroboration of its promoting interferon (IFN)- $\gamma$-dependent antitumor responses in a lung cancer model (Hillinger et al., 2003; Cao et al., 2007); and high CCR7 expression was strongly related to $\mathrm{CrkL}$ and c-ABL kinase mRNA expression and could improve postoperative prognosis of lung adenocarcinoma patients (Itakura et al., 2013). In addition, a phase-1 clinical trial of immunotherapy found that DCs expressing CCR7 receptor ligand CCL21 administrated into lung tumors could enhance immunity and subsequently make the tumor shrink (Sharma et al., 2013). Consequently, this chemokine axis is like a double-edged sword acting for both good and bad according to the particular microenvironment during lung cancer progression and metastasis.

\section{CCL25/CCR9}

The natural ligand of CCR9, CCL25, is a thymusexpressed chemokine, which has been found primarily in the involvement of immune homeostasis and then in human solid tumors such as colorectal, prostate, ovarian, and breast cancers with relation to tumor invasion and metastasis (Singh et al., 2004; Svensson and Agace, 2006; Johnson-Holiday et al., 2011; Singh et al., 2011; Chen et al., 2012). However, the study of the CCL25/CCR9 axis on lung cancer is limited; so far, only one study has found that its expression correlated with aggressiveness and mediated key steps of metastasis in clinical samples and cell lines of NSCLC, especially in adenocarcinomas compared with squamous cell carcinomas, due to differential expression of matrix metalloproteinases and tissue inhibitor of metalloproteinases under the influence of CCL25 (Gupta et al., 2014). Further and more studies are needed to explore the exact effect of the CCL25/CCR9 axis on lung cancer. If it does act as a pro-metastasis factor, targeting it would be of assistance in comprehensive tumor treatments.

\section{CCL4/CCR5}

CCL4, the ligand of CCR5, was found to enhance expression of stromal-derived factor-erythroid differentiation regulator 1 (ERDR1), which could promote cancer cell survival. CCR5 on pulmonary mesenchymal cells could promote experimental metastasis via the induction of ERDR1 (Mango et al., 2014), while deficiency of CCR5 suppressed tumor development by means of inactivation of nuclear factor- $\mathrm{KB}(\mathrm{NF}-\mathrm{\kappa B})$ and inhibition of monocyte chemoattractant protein-1 (MCP-1) in an urethane-induced lung tumor model (Lee et al., 2012). Accordingly, the CCL4/CCR5 axis seems to play a role in lung tumor progression and metastasis. Investigations of lung cancer patients should be conducted to test the effect in the future.

\section{Atypical chemokine receptors}

Atypical chemokine receptors including three members, the Duffy antigen receptor for chemokines (DARC), D6, and the ChemocentryX chemokine receptor (CCX-CKR), differ from other typical chemokine receptors, because they can efficiently internalize their cognate chemokine ligands without inducing a signaling cascade acting as chemokine scavengers.

In lung cancer, DARC-expressing A549 cells were observed to have a significant reduction in cellularity, increased levels of necrosis, lower microvessel 
density, and decreased metastasis (Addison et al., 2004). D6 could inhibit human NSCLC growth by sequestration of some chemokines like CCL2, CCL4, and CCL5 (Wu et al., 2013).

It was reported that CCX-CKR acted as a negative regulator of growth and metastasis in breast cancer mainly by sequestration of homeostatic chemokines such as CCL19, CCL21, CCL25, and CXCL13, and subsequent inhibition of intratumoral neovascularity (Feng et al., 2009). However, studies on CCX-CKR expression status and its relation to tumor progression and invasion are lacking for lung cancer to date.

\section{Conclusions}

In conclusion, a group of chemokines and their receptors are aberrantly expressed during lung tumorigenesis, progression, and metastasis, leading to an unbalance of the tumor microenvironment. Overexpressed pro-tumor chemokines and receptors are correlated with poor prognosis, and thus diagnoses and treatments targeted at them could bring a bright future for lung cancer patients. Although normally expressed anti-tumor chemokines and their receptors may be correlated with better prognosis, further studies are needed to elucidate them for human lung cancers and translate this into clinical utilization.

\section{Compliance with ethics guidelines}

Zeng-hui CHENG, Yu-xin SHI, Min YUAN, Dan XIONG, Jiang-hua ZHENG, and Zhi-yong ZHANG declare that they have no conflict of interest.

This article does not contain any studies with human or animal subjects performed by any of the authors.

\section{References}

Acosta, J.C., O'Loghlen, A., Banito, A., et al., 2008. Chemokine signaling via the CXCR2 receptor reinforces senescence. Cell, 133(6):1006-1018. http://dx.doi.org/10.1016/j.cell.2008.03.038

Addison, C.L., Belperio, J.A., Burdick, M.D., et al., 2004. Overexpression of the duffy antigen receptor for chemokines (DARC) by NSCLC tumor cells results in increased tumor necrosis. BMC Cancer, 4(1):28. http://dx.doi.org/10.1186/1471-2407-4-28

Almasi, C.E., Drivsholm, L., Pappot, H., et al., 2013. The liberated domain I of urokinase plasminogen activator receptor-a new tumour marker in small cell lung cancer. APMIS, 121(3):189-196. http://dx.doi.org/10.1111/j.1600-0463.2012.02955.x

Al Zobair, A.A., Al Obeidy, B.F., Yang, L., et al., 2013. Concomitant overexpression of EGFR and CXCR4 is associated with worse prognosis in a new molecular subtype of non-small cell lung cancer. Oncol. Rep., 29(4): 1524-1532.

http://dx.doi.org/10.3892/or.2013.2254

Arenberg, D.A., Keane, M.P., DiGiovine, B., et al., 1998. Epithelial-neutrophil activating peptide (ENA-78) is an important angiogenic factor in non-small cell lung cancer. J. Clin. Invest., 102(3):465-472.

http://dx.doi.org/10.1172/JCI3145

Balkwill, F., 2004. The significance of cancer cell expression of the chemokine receptor CXCR4. Semin. Cancer Biol., 14(3):171-179.

http://dx.doi.org/10.1016/j.semcancer.2003.10.003

Bauer, A.K., Hill III, T., Alexander, C.M., 2013. The involvement of NRF2 in lung cancer. Oxid. Med. Cell. Longev., 2013:746432.

http://dx.doi.org/10.1155/2013/746432

Belperio, J.A., Phillips, R.J., Burdick, M.D., et al., 2004. The SDF-1/CXCL 12/CXCR4 biological axis in non-small cell lung cancer metastases. Chest, 125(Suppl. 5):156S. http://dx.doi.org/10.1378/chest.125.5_suppl.156S

Burger, J.A., Kipps, T.J., 2006. CXCR4: a key receptor in the crosstalk between tumor cells and their microenvironment. Blood, 107(5):1761-1767.

http://dx.doi.org/10.1182/blood-2005-08-3182

Burger, J.A., Gribben, J.G., 2014. The microenvironment in chronic lymphocytic leukemia (CLL) and other B cell malignancies: insight into disease biology and new targeted therapies. Semin. Cancer Biol., 24:71-81. http://dx.doi.org/10.1016/j.semcancer.2013.08.011

Burger, J.A., Stewart, D.J., Wald, O., et al., 2011. Potential of CXCR4 antagonists for the treatment of metastatic lung cancer. Expert Rev. Anticancer Ther., 11(4):621-630. http://dx.doi.org/10.1586/era.11.11

Cabioglu, N., Gong, Y., Islam, R., et al., 2007. Expression of growth factor and chemokine receptors: new insights in the biology of inflammatory breast cancer. Ann. Oncol., 18(6):1021-1029. http://dx.doi.org/10.1093/annonc/mdm060

Cao, M., Deng, H.X., Zhao, J., et al., 2007. Antitumour activity of cationic-liposome-conjugated adenovirus containing the CCL19 [chemokine (C-C motif) ligand 19] gene. Biotechnol. Appl. Biochem., 48(2):109-116.

Caunt, M., Hu, L., Tang, T., et al., 2006. Growth-regulated oncogene is pivotal in thrombin-induced angiogenesis. Cancer Res., 66(8):4125-4132. http://dx.doi.org/10.1158/0008-5472.CAN-05-2570

Chen, H.J., Edwards, R., Tucci, S., et al., 2012. Chemokine 25-induced signaling suppresses colon cancer invasion and metastasis. J. Clin. Invest., 122(9):3184-3196. http://dx.doi.org/10.1172/JCI62110

Chen, W., Gao, Q., Han, S., et al., 2015. The CCL2/CCR2 axis 
enhances IL-6-induced epithelial-mesenchymal transition by cooperatively activating STAT3-Twist signaling. Tumour. Biol., 36(2):973-981. http://dx.doi.org/10.1007/s13277-014-2717-z

Damelin, M., Geles, K.G., Follettie, M.T., et al., 2011. Delineation of a cellular hierarchy in lung cancer reveals an oncofetal antigen expressed on tumor-initiating cells. Cancer Res., 71(12):4236-4246. http://dx.doi.org/10.1158/0008-5472.CAN-10-3919

Dass, K., Ahmad, A., Azmi, A.S., et al., 2008. Evolving role of uPA/uPAR system in human cancers. Cancer Treat. Rev., 34(2):122-136. http://dx.doi.org/10.1016/j.ctrv.2007.10.005

Ding, Y., Shimada, Y., Maeda, M., et al., 2003. Association of $\mathrm{CC}$ chemokine receptor 7 with lymph node metastasis of esophageal squamous cell carcinoma. Clin. Cancer Res., 9(9):3406-3412.

Dong, J., Dai, J., Shu, Y., et al., 2010. Polymorphisms in EGFR and VEGF contribute to non-small-cell lung cancer survival in a Chinese population. Carcinogenesis, 31(6): 1080-1086. http://dx.doi.org/10.1093/carcin/bgq079

Eramo, A., Lotti, F., Sette, G., et al., 2008. Identification and expansion of the tumorigenic lung cancer stem cell population. Cell Death Differ., 15(3):504-514. http://dx.doi.org/10.1038/sj.cdd.4402283

Feng, L.Y., Ou, Z.L., Wu, F.Y., et al., 2009. Involvement of a novel chemokine decoy receptor CCX-CKR in breast cancer growth, metastasis and patient survival. Clin. Cancer Res., 15(9):2962-2970. http://dx.doi.org/10.1158/1078-0432.CCR-08-2495

Goldstraw, P., Crowley, J., Chansky, K., et al., 2007. The IASLC Lung Cancer Staging Project: proposals for the revision of the TNM stage groupings in the forthcoming (seventh) edition of the TNM Classification of Malignant Tumours. J. Thorac. Oncol., 2(8):706-714. http://dx.doi.org/10.1097/JTO.0b013e31812f3c1a

Gong, L., Cumpian, A.M., Caetano, M.S., et al., 2013. Promoting effect of neutrophils on lung tumorigenesis is mediated by CXCR2 and neutrophil elastase. Mol. Cancer, 12(1):154. http://dx.doi.org/10.1186/1476-4598-12-154

Groome, P.A., Bolejack, V., Crowley, J.J., et al., 2007. The IASLC Lung Cancer Staging Project: validation of the proposals for revision of the $\mathrm{T}, \mathrm{N}$, and $\mathrm{M}$ descriptors and consequent stage groupings in the forthcoming (seventh) edition of the TNM classification of malignant tumours. $J$. Thorac. Oncol., 2(8):694-705. http://dx.doi.org/10.1097/JTO.0b013e31812d05d5

Gupta, P., Sharma, P.K., Mir, H., et al., 2014. CCR9/CCL25 expression in non-small cell lung cancer correlates with aggressive disease and mediates key steps of metastasis. Oncotarget, 5(20):10170-10179.

http://dx.doi.org/10.18632/oncotarget.2526

Hillinger, S., Yang, S.C., Zhu, L., et al., 2003. EBV-induced molecule 1 ligand chemokine (ELC/CCL19) promotes IFN- $\gamma$-dependent antitumor responses in a lung cancer model. J. Immunol., 171(12):6457-6465.

http://dx.doi.org/10.4049/jimmunol.171.12.6457

Hu, T., Yao, Y., Yu, S., et al., 2014. CXCR4 and Nrf2 expressions in non-small cell lung cancer and their clinical implications. J. South Med. Univ., 34(2):153-158.

Iijima, N., Yanagawa, Y., Clingan, J.M., et al., 2005. CCR7-mediated c-Jun N-terminal kinase activation regulates cell migration in mature dendritic cells. Int. Immunol., 17(9):1201-1212. http://dx.doi.org/10.1093/intimm/dxh297

Itakura, M., Terashima, Y., Shingyoji, M., et al., 2013. High $\mathrm{CC}$ chemokine receptor 7 expression improves postoperative prognosis of lung adenocarcinoma patients. Br. J. Cancer, 109(5):1100-1108. http://dx.doi.org/10.1038/bjc. 2013.440

Johnson-Holiday, C., Singh, R., Johnson, E., et al., 2011. CCL25 mediates migration, invasion and matrix metalloproteinase expression by breast cancer cells in a CCR9-dependent fashion. Int. J. Oncol., 38(5):1279-1285. http://dx.doi.org/10.3892/ijo.2011.953

Jung, M.J., Rho, J.K., Kim, Y.M., et al., 2013. Upregulation of CXCR4 is functionally crucial for maintenance of stemness in drug-resistant non-small cell lung cancer cells. Oncogene, 32(2):209-221. http://dx.doi.org/10.1038/onc.2012.37

Keeley, E.C., Mehrad, B., Strieter, R.M., 2011. Chemokines as mediators of tumor angiogenesis and neovascularization. Exp. Cell Res., 317(5):685-690. http://dx.doi.org/10.1016/j.yexcr.2010.10.020

Keith, R.L., Miller, Y.E., 2013. Lung cancer chemoprevention: current status and future prospects. Nat. Rev. Clin. Oncol., 10(6):334-343.

http://dx.doi.org/10.1038/nrclinonc.2013.64

Kudo-Saito, C., Shirako, H., Ohike, M., et al., 2013. CCL2 is critical for immunosuppression to promote cancer metastasis. Clin. Exp. Metastasis, 30(4):393-405. http://dx.doi.org/10.1007/s10585-012-9545-6

Lee, N.J., Choi, D.Y., Song, J.K., et al., 2012. Deficiency of $\mathrm{C}-\mathrm{C}$ chemokine receptor 5 suppresses tumor development via inactivation of NF- $\mathrm{KB}$ and inhibition of monocyte chemoattractant protein-1 in urethane-induced lung tumor model. Carcinogenesis, 33(12):2520-2528. http://dx.doi.org/10.1093/carcin/bgs265

Li, X., Tai, H.H., 2013. Activation of thromboxane A2 receptor (TP) increases the expression of monocyte chemoattractant protein-1 (MCP-1)/chemokine (C-C motif) ligand 2 (CCL2) and recruits macrophages to promote invasion of lung cancer cells. PLoS ONE, 8(1):e54073. http://dx.doi.org/10.1371/journal.pone.0054073

Li, X., Tai, H.H., 2014. Thromboxane A2 receptor-mediated release of matrix metalloproteinase-1 (MMP-1) induces expression of monocyte chemoattractant protein-1 (MCP-1) by activation of protease-activated receptor 2 
(PAR2) in A549 human lung adenocarcinoma cells. Mol. Carcinog., 53(8):659-666.

http://dx.doi.org/10.1002/mc.22020

Li, Y., Shen, Y., Miao, Y., et al., 2014. Co-expression of uPAR and CXCR4 promotes tumor growth and metastasis in small cell lung cancer. Int. J. Clin. Exp. Pathol., 7(7): 3771-3780.

Lo, H.M., Shieh, J.M., Chen, C.L., et al., 2013. Vascular endothelial growth factor induces CXCL1 chemokine release via JNK and PI-3K-dependent pathways in human lung carcinoma epithelial cells. Int. J. Mol. Sci., 14(5): 10090-10106. http://dx.doi.org/10.3390/ijms140510090

Luppi, F., Longo, A.M., de Boer, W.I., et al., 2007. Interleukin-8 stimulates cell proliferation in non-small cell lung cancer through epidermal growth factor receptor transactivation. Lung Cancer, 56(1):25-33. http://dx.doi.org/10.1016/j.lungcan.2006.11.014

Majetschak, M., 2011. Extracellular ubiquitin: immune modulator and endogenous opponent of damage-associated molecular pattern molecules. J. Leukoc. Biol., 89(2): 205-219.

http://dx.doi.org/10.1189/jlb.0510316

Mango, R.L., Wu, Q.P., West, M., et al., 2014. C-C chemokine receptor 5 on pulmonary mesenchymal cells promotes experimental metastasis via the induction of erythroid differentiation regulator 1. Mol. Cancer Res., 12(2):274-282. http://dx.doi.org/10.1158/1541-7786.MCR-13-0164

Mantovani, A., Savino, B., Locati, M., et al., 2010. The chemokine system in cancer biology and therapy. Cytokine Growth Factor Rev., 21(1):27-39. http://dx.doi.org/10.1016/j.cytogfr.2009.11.007

Maxwell, P.J., Gallagher, R., Seaton, A., et al., 2007. HIF-1 and NF-kB-mediated upregulation of CXCR1 and CXCR2 expression promotes cell survival in hypoxic prostate cancer cells. Oncogene, 26(52):7333-7345. http://dx.doi.org/10.1038/sj.onc.1210536

Mazar, A.P., 2008. Urokinase plasminogen activator receptor choreographs multiple ligand interactions: implications for tumor progression and therapy. Clin. Cancer Res., 14(18):5649-5655. http://dx.doi.org/10.1158/1078-0432.CCR-07-4863

Montuori, N., Bifulco, K., Carriero, M.V., et al., 2011. The cross-talk between the urokinase receptor and fMLP receptors regulates the activity of the CXCR4 chemokine receptor. Cell. Mol. Life Sci., 68(14):2453-2467. http://dx.doi.org/10.1007/s00018-010-0564-7

Mukaida, N., Baba, T., 2012. Chemokines in tumor development and progression. Exp. Cell Res., 318(2): 95-102. http://dx.doi.org/10.1016/j.yexcr.2011.10.012

Muller, A., Homey, B., Soto, H., et al., 2001. Involvement of chemokine receptors in breast cancer metastasis. Nature, 410(6824):50-56. http://dx.doi.org/10.1038/35065016
National Lung Screening Trial Research, 2011. Reduced lung-cancer mortality with low-dose computed tomographic screening. N. Engl. J. Med., 365(5):395-409. http://dx.doi.org/10.1056/NEJMoa1 102873

Numasaki, M., Watanabe, M., Suzuki, T., et al., 2005. IL-17 enhances the net angiogenic activity and in vivo growth of human non-small cell lung cancer in SCID mice through promoting CXCR-2-dependent angiogenesis. J. Immunol., 175(9):6177-6189. http://dx.doi.org/10.4049/jimmunol.175.9.6177

Peled, A., Wald, O., Burger, J., 2012. Development of novel CXCR4-based therapeutics. Expert Opin. Investig. Drugs, 21(3):341-353. http://dx.doi.org/10.1517/13543784.2012.656197

Phillips, R.J., Burdick, M.D., Lutz, M., et al., 2003. The stromal derived factor-1/CXCL12-CXC chemokine receptor 4 biological axis in non-small cell lung cancer metastases. Am. J. Respir. Crit. Care Med., 167(12): 1676-1686. http://dx.doi.org/10.1164/rccm.200301-071OC

Phillips, R.J., Mestas, J., Gharaee-Kermani, M., et al., 2005. Epidermal growth factor and hypoxia-induced expression of CXC chemokine receptor 4 on non-small cell lung cancer cells is regulated by the phosphatidylinositol 3-kinase/PTEN/AKT/mammalian target of rapamycin signaling pathway and activation of hypoxia inducible factor-1 $\alpha$. J. Biol. Chem., 280(23):22473-22481. http://dx.doi.org/10.1074/jbc.M500963200

Ploug, M., Ellis, V., 1994. Structure-function relationships in the receptor for urokinase-type plasminogen activator. Comparison to other members of the Ly- 6 family and snake venom $\alpha$-neurotoxins. FEBS Lett., 349(2):163-168. http://dx.doi.org/10.1016/0014-5793(94)00674-1

Richmond, A., 2002. Nf-кB, chemokine gene transcription and tumour growth. Nat. Rev. Immunol., 2(9):664-674. http://dx.doi.org/10.1038/nri887

Saini, V., Marchese, A., Majetschak, M., 2010. CXC chemokine receptor 4 is a cell surface receptor for extracellular ubiquitin. J. Biol. Chem., 285(20):15566-15576. http://dx.doi.org/10.1074/jbc.M110.103408

Saintigny, P., Burger, J.A., 2012. Recent advances in nonsmall cell lung cancer biology and clinical management. Discov. Med., 13(71):287-297.

Saintigny, P., Massarelli, E., Lin, S., et al., 2013. CXCR2 expression in tumor cells is a poor prognostic factor and promotes invasion and metastasis in lung adenocarcinoma. Cancer Res., 73(2):571-582. http://dx.doi.org/10.1158/0008-5472.CAN-12-0263

Sarvaiya, P.J., Guo, D., Ulasov, I., et al., 2013. Chemokines in tumor progression and metastasis. Oncotarget, 4(12): 2171-2185. http://dx.doi.org/10.18632/oncotarget.1426

Scapini, P., Morini, M., Tecchio, C., et al., 2004. CXCL1/ macrophage inflammatory protein-2-induced angiogenesis in vivo is mediated by neutrophil-derived vascular 
endothelial growth factor-A. J. Immunol., 172(8):50345040 .

http://dx.doi.org/10.4049/jimmunol.172.8.5034

Schioppa, T., Uranchimeg, B., Saccani, A., et al., 2003. Regulation of the chemokine receptor CXCR4 by hypoxia. J. Exp. Med., 198(9):1391-1402. http://dx.doi.org/10.1084/jem.20030267

Sharma, S., Zhu, L., Srivastava, M.K., et al., 2013. CCL21 chemokine therapy for lung cancer. Int. Trends Immun., 1(1):10-15.

Siegel, R., Naishadham, D., Jemal, A., 2012a. Cancer statistics, 2012. CA Cancer J. Clin., 62(1):10-29. http://dx.doi.org/10.3322/caac.20138

Siegel, R., DeSantis, C., Virgo, K., et al., 2012b. Cancer treatment and survivorship statistics, 2012. CA Cancer J. Clin., 62(4):220-241. http://dx.doi.org/10.3322/caac.21149

Singh, R., Stockard, C.R., Grizzle, W.E., et al., 2011. Expression and histopathological correlation of CCR9 and CCL25 in ovarian cancer. Int. J. Oncol., 39(2): 373-381. http://dx.doi.org/10.3892/ijo.2011.1059

Singh, S., Singh, U.P., Stiles, J.K., et al., 2004. Expression and functional role of CCR9 in prostate cancer cell migration and invasion. Clin. Cancer Res., 10(24):8743-8750. http://dx.doi.org/10.1158/1078-0432.CCR-04-0266

Sparmann, A., Bar-Sagi, D., 2004. Ras-induced interleukin-8 expression plays a critical role in tumor growth and angiogenesis. Cancer Cell, 6(5):447-458. http://dx.doi.org/10.1016/j.ccr.2004.09.028

Su, L., Zhang, J., Xu, H., et al., 2005. Differential expression of CXCR4 is associated with the metastatic potential of human non-small cell lung cancer cells. Clin. Cancer Res., 11(23):8273-8280. http://dx.doi.org/10.1158/1078-0432.CCR-05-0537

Sun, H., Chung, W.C., Ryu, S.H., et al., 2008. Cyclic AMPresponsive element binding protein- and nuclear factor$\kappa \mathrm{B}$-regulated $\mathrm{CXC}$ chemokine gene expression in lung carcinogenesis. Cancer Prev. Res. (Phila), 1(5):316-328. http://dx.doi.org/10.1158/1940-6207.CAPR-07-0002

Sun, X., Cheng, G., Hao, M., et al., 2010. CXCL12/CXCR4/ CXCR7 chemokine axis and cancer progression. Cancer Metastasis Rev., 29(4):709-722. http://dx.doi.org/10.1007/s10555-010-9256-x

Sutherland, K.D., Berns, A., 2010. Cell of origin of lung cancer. Mol. Oncol., 4(5):397-403. http://dx.doi.org/10.1016/j.molonc.2010.05.002

Suzuki, M., Mohamed, S., Nakajima, T., et al., 2008. Aberrant methylation of CXCL12 in non-small cell lung cancer is associated with an unfavorable prognosis. Int. J. Oncol., 33(1):113-119.

Svensson, M., Agace, W.W., 2006. Role of CCL25/CCR9 in immune homeostasis and disease. Expert Rev. Clin. Immunol., 2(5):759-773. http://dx.doi.org/10.1586/1744666X.2.5.759
Wagner, P.L., Hyjek, E., Vazquez, M.F., et al., 2009. CXCL12 and CXCR4 in adenocarcinoma of the lung: association with metastasis and survival. J. Thorac. Cardiovasc. Surg., 137(3):615-621. http://dx.doi.org/10.1016/j.jtcvs.2008.07.039

Wald, O., Izhar, U., Amir, G., et al., 2011. Interaction between neoplastic cells and cancer-associated fibroblasts through the CXCL12/CXCR4 axis: role in non-small cell lung cancer tumor proliferation. J. Thorac. Cardiovasc. Surg., 141(6): 1503-1512. http://dx.doi.org/10.1016/j.jtcvs.2010.11.056

Wang, L., Wang, Z., Liu, X., et al., 2014. High-level C-X-C chemokine receptor type 4 expression correlates with brain-specific metastasis following complete resection of non-small cell lung cancer. Oncol. Lett., 7(6):1871-1876. http://dx.doi.org/10.3892/ol.2014.1979

Wislez, M., Fujimoto, N., Izzo, J.G., et al., 2006. High expression of ligands for chemokine receptor CXCR2 in alveolar epithelial neoplasia induced by oncogenic kras. Cancer Res., 66(8):4198-4207. http://dx.doi.org/10.1158/0008-5472.CAN-05-3842

Wu, F.Y., Fan, J., Tang, L., et al., 2013. Atypical chemokine receptor D6 inhibits human non-small cell lung cancer growth by sequestration of chemokines. Oncol. Lett., 6(1):91-95 http://dx.doi.org/10.3892/ol.2013.1358

Xie, S., Zeng, W., Fan, G., et al., 2014. Effect of CXCL12/ CXCR4 on increasing the metastatic potential of non-small cell lung cancer is inhibited through the downregulation of CXCR4 chemokine receptor expression. Oncol. Lett., 7(4):941-947. http://dx.doi.org/10.3892/ol.2014.1837

Yan, L., Cai, Q., Xu, Y., 2013. The ubiquitin-CXCR4 axis plays an important role in acute lung infection-enhanced lung tumor metastasis. Clin. Cancer Res., 19(17):47064716. http://dx.doi.org/10.1158/1078-0432.CCR-13-0011

Yanagawa, J., Walser, T.C., Zhu, L.X., et al., 2009. Snail promotes CXCR2 ligand-dependent tumor progression in non-small cell lung carcinoma. Clin. Cancer Res., 15(22): 6820-6829. http://dx.doi.org/10.1158/1078-0432.CCR-09-1558

Yang, L., Li, L., Chen, Y., et al., 2005a. Mortality time trends and the incidence and mortality estimation and projection for lung cancer in China. Chin. J. Lung Cancer, 8(4): 274-278. http://dx.doi.org/10.3779/j.issn.1009-3419.2005.04.05

Yang, L., Parkin, D.M., Ferlay, J., et al., 2005b. Estimates of cancer incidence in China for 2000 and projections for 2005. Cancer Epidemiol. Biomarkers Prev., 14(1):243-250.

Zhang, Q., Sun, L., Yin, L., et al., 2013. CCL19/CCR7 upregulates heparanase via specificity protein-1 (Sp1) to promote invasion of cell in lung cancer. Tumour. Biol., 34(5):2703-2708. http://dx.doi.org/10.1007/s13277-013-0822-z 
Zhang, X.W., Qin, X., Qin, C.Y., et al., 2013. Expression of monocyte chemoattractant protein-1 and CC chemokine receptor 2 in non-small cell lung cancer and its significance. Cancer Immunol. Immunother., 62(3):563-570. http://dx.doi.org/10.1007/s00262-012-1361-y

Zlotnik, A., Yoshie, O., 2000. Chemokines: a new classification system and their role in immunity. Immunity, 12(2): 121-127.

http://dx.doi.org/10.1016/S1074-7613(00)80165-X

\section{中文概要}

题 目: 趋化因子及其受体在肺癌侵袭与转移过程中的作用

概 要: 本文对近年来与肺癌侵袭、转移相关的趋化因子 轴及其可能的机制进行综述, 为靶向治疗提供理 论线索, 并预测促癌趋化因子轴的激活与抑癌趋 化因子轴的失活可能导致了肺癌的侵袭与转移。

关键词: 肺癌; 趋化因子; 肿瘤进展; 转移 